\title{
Norepinephrine potentiates the efficacy of volume expansion on mean systemic pressure in septic shock
}

\author{
Imane Adda* ${ }^{*}$, Christopher Lai, Jean-Louis Teboul, Laurent Guerin, Francesco Gavelli and Xavier Monnet
}

\begin{abstract}
Background: Through venous contraction, norepinephrine (NE) increases stressed blood volume and mean systemic pressure (Pms) and exerts a "fluid-like" effect. When both fluid and NE are administered, Pms may not only result from the sum of the effects of both drugs. Indeed, norepinephrine may enhance the effects of volume expansion: because fluid dilutes into a more constricted, smaller, venous network, fluid may increase Pms to a larger extent at a higher than at a lower dose of NE. We tested this hypothesis, by mimicking the effects of fluid by passive leg raising (PLR).
\end{abstract}

Methods: In 30 septic shock patients, norepinephrine was decreased to reach a predefined target of mean arterial pressure (65-70 mmHg by default, $80-85 \mathrm{mmHg}$ in previously hypertensive patients). We measured the PLR-induced increase in Pms (heart-lung interactions method) under high and low doses of norepinephrine. Preload responsiveness was defined by a PLR-induced increase in cardiac index $\geq 10 \%$.

Results: Norepinephrine was decreased from 0.32 [0.18-0.62] to $0.26[0.13-0.50] \mu \mathrm{g} / \mathrm{kg} / \mathrm{min}(p<0.0001)$. This significantly decreased the mean arterial pressure by $10[7-20] \%$ and Pms by $9[4-19] \%$. The increase in Pms ( $\triangle \mathrm{Pms}$ ) induced by PLR was 13 [9-19]\% at the higher dose of norepinephrine and $11[6-16] \%$ at the lower dose $(p<0.0001)$. Pms reached during PLR at the high dose of NE was higher than expected by the sum of Pms at baseline at low dose, $\triangle P$ ms induced by changing the norepinephrine dose and $\triangle P$ ms induced by PLR at low dose of NE (35.6 [11.2] mmHg vs. $33.6[10.9] \mathrm{mmHg}$, respectively, $p<0.01)$. The number of preload responders was $8(27 \%)$ at the high dose of NE and 15 (50\%) at the low dose.

Conclusions: Norepinephrine enhances the Pms increase induced by PLR. These results suggest that a bolus of fluid of the same volume has a greater haemodynamic effect at a high dose than at a low dose of norepinephrine during septic shock.

Keywords: Vasopressors, Heart-lung interactions, Fluid balance, Cardiac preload, Venous return

\section{Take-home message}

Norepinephrine enhances the increase in mean systemic pressure induced by a passive leg raising. This suggests that norepinephrine and fluid therapy may

\footnotetext{
*Correspondence: imane.adda@aphp.fr
}

AP-HP, Service de médecine intensive-réanimation, Hôpital de Bicêtre, DMU CORREVE, Inserm UMR S_999, FHU SEPSIS, Groupe de Recherche Clinique CARMAS, Université Paris-Saclay, 78, Rue du Général Leclerc,

94270 Le Kremlin-Bicêtre, France exert cumulative haemodynamic effects in septic shock patients.

\section{Background}

Volume expansion and norepinephrine (NE) are the main pillars of the haemodynamic support in septic shock, and their cardiovascular properties have been extensively studied. In particular, some studies have focused on the NE effects on venous return [1-5]. They have shown that by constricting veins as it constricts arteries, NE reduces 
the venous capacitance and increases the mean systemic filling pressure (Pms) [1-3]. The resulting increase in cardiac preload is of significant amplitude in clinical practice $[4,5]$, so that NE increases cardiac output in case of preload responsiveness $[2,5]$.

In addition to this fluid-like effect, NE might also potentiate the effects of volume expansion on Pms in a "cumulative" way. By reducing the capacitance of the venous tank, NE might enhance the increase in stressed blood volume provoked by fluid administration [3]. The same volume of fluid might increase Pms to a larger extent at a higher than at a lower dose of NE. In such a case, administering both NE and fluid would exert an effect on Pms which would be larger than the addition of the effect of each treatment. NE would potentiate the effects of volume expansion on Pms.

The present study investigated this hypothesis. Its purpose was to test, in patients with septic shock, if the amplitude of the change in Pms induced by a volume challenge would be larger at a higher than at a lower dose of NE, suggesting cumulative effects between NE and volume expansion. For this purpose, we used the estimation of Pms and resistance to venous return developed by Maas et al. [1]. The volume challenge was performed by passive leg raising (PLR), which mimics volume expansion by exerting comparable effects on venous return determinants [6] and which is fully reversible [7].

\section{Methods}

\section{Study population}

This study was conducted in the 25-bed medical intensive care unit of Paris-Saclay university, Bicêtre hospital, from March to September 2018. It was approved by the institutional review board of our institution (Comite pour la protection des personnes Ile-de-France VII). Patients or their next of kin were informed about the study and accepted to participate.

Patients were included if they met all the following criteria: septic shock [7], continuous intravenous administration of NE, mechanical ventilation in the volume assist-control mode (Evita 4 or V500, Dräger, Lübeck, Germany), haemodynamic monitoring by a PiCCO2 device (PULSION Medical Systems, Feldkirchen, Germany), haemodynamic stability as defined by no change in the mean arterial pressure and in cardiac index (CI) $>10 \%$ for at least $30 \mathrm{~min}$ [2], decision of the attending physicians to decrease the dose of NE in order to reach a predefined target of mean arterial pressure (65-70 $\mathrm{mmHg}$ by default, $80-85 \mathrm{mmHg}$ in previously hypertensive patients [8]). Patients were not included consecutively but depending on the availability of the investigators.
Patients were excluded in case of age $<18$ years, pregnancy, head trauma (contraindication to PLR) and intraabdominal hypertension [9] or venous compression stockings (both responsible for some false-negatives of the PLR test).

\section{Study design}

At baseline, we performed a first set of measurements, including Pms and resistance to venous return as shown in Fig. 1. A PLR was then performed by moving the patient from the semi-recumbent position at $45^{\circ}$ to a position where the legs are elevated at $45^{\circ}$ and the trunk is horizontal [10]. After one minute and stabilisation of CI, transpulmonary thermodilution was performed. Then, a second set of measurements was performed as at baseline, including Pms and resistance to venous return. The patient was then moved back to the initial semirecumbent position.

After the first set of measurement, the dose of NE was decreased in one step, as decided by the clinician in charge of the patient, with the aim of reaching a mean arterial pressure corresponding to the prescribed target [11]. If this decrease induced hypotension, the dose of NE was increased. In any case, after the last change of the dose of NE, stability was allowed for at least $30 \mathrm{~min}$. Once the dose of NE was decreased, it was kept stable for the rest of the study.

After stabilisation, a transpulmonary thermodilution was performed, and a series of measurements was performed as at the high dose of NE. A second PLR was started. One minute later, measurements were recorded again (Fig. 1). The patient was returned to the semirecumbent position. All other treatments were kept unchanged during the study period. The same operator performed all the measurements of the patient in order to avoid an operator-dependent effect [12].

\section{Measurements \\ Haemodynamic measurements}

The arterial and central venous pressure sensors were placed at the level of the mid-axillary line, and zeroing was performed against atmospheric pressure. Airway pressure was measured at the proximal extremity of the endotracheal tube. Arterial pressure, central venous pressure (CVP), and airway pressure were continuously computerised using the HEM 4.2 data acquisition software (Notocord, Croissy sur Seine, France). CI was measured by the $\mathrm{PiCCO} 2$ device through transpulmonary thermodilution [13] and pulse contour analysis [14]. The beat-to-beat values of stroke volume derived from pulse contour analysis performed by the $\mathrm{PiCCO} 2$ device were computerised by using the PiCCOWin 4.0 software (Pulsion Medical Systems, Feldkirchen, Germany). 


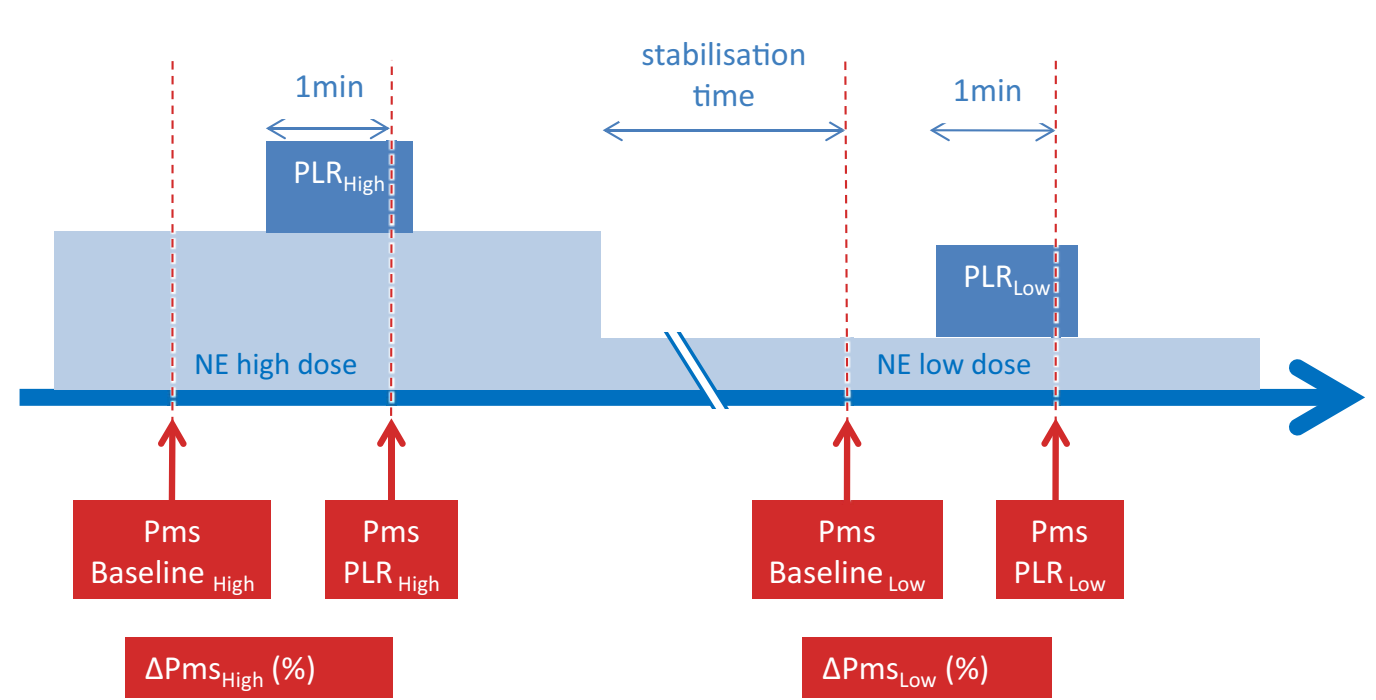

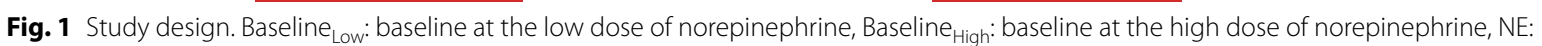
norepinephrine, $P L R_{L o w}$ : passive leg raising at the low dose of norepinephrine; $P L R_{\text {High }}$ : passive leg raising at the high dose of norepinephrine, $P m s$ : mean systemic pressure, $\triangle \mathrm{Pms}$ : changes in mean systemic pressure induced by passive leg raising

Calibration of pulse contour analysis-derived stroke volume was performed by using transpulmonary thermodilution, with injection of three 15 -mL cold saline boluses $[15,16]$. Through transpulmonary thermodilution, we also measured the cardiac function index (estimation of the left ventricular systolic function) [17].

\section{Pms and resistance to venous return}

Pms and the resistance to venous return were determined by constructing an estimated venous return curve by using the haemodynamic effects of heart-lung interactions. This "heart-lung interactions method" has been previously described $[1,2]$.

Briefly, it is based on the principle that the venous return curve is the relationship between right atrial pressure and venous return according to the Guyton's model. A series of two 15-s end-inspiratory occlusions and of two 15-s end-expiratory occlusions were performed at the level of positive end-expiratory pressure (PEEP) which was adjusted before the beginning of the study for reaching a plateau pressure of $28-30 \mathrm{cmH}_{2} \mathrm{O}$ and kept constant throughout the entire study procedure.

The four occlusions were performed in a random order. During respiratory occlusions, the extreme value of $\mathrm{CI}$ (minimal for inspiratory occlusions, maximal for expiratory occlusions) measured by pulse contour analysis reached was averaged over the two last seconds of occlusions. The extreme value of CVP (minimal for expiratory occlusions, maximal for inspiratory occlusions) was recorded at the same time. Each ventilatory occlusion allowed us to obtain a couple of measurements of $\mathrm{CI}$ and CVP.

The couple of CI and CVP values was reported on a graph (Excel, Microsoft, Redmond, WA) with CVP on the $\mathrm{x}$-axis (as an estimate of right atrial pressure) and $\mathrm{CI}$ on the $\mathrm{y}$-axis (as an estimate of venous return, since venous return and cardiac output are equal at steady state) (Additional file 1: figure S1). Then, the regression line between these points was computed by using the least-squares method (Excel, Microsoft, Redmond, WA). Pms was estimated as the pressure at the $\mathrm{x}$-intercept of the regression line, as shown in Additional file 1: figure S1. The resistance to venous return was estimated from the inverse of the slope of the regression line.

\section{Data analysis}

In order to test our hypothesis that NE potentiates the effects of volume expansion on Pms, we compared for each patient the value of Pms that was actually observed

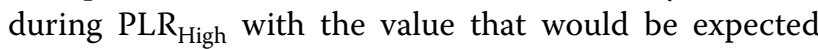
during $\mathrm{PLR}_{\mathrm{High}}$ if it resulted only from the sum of the effects of PLR and of increasing the dose of NE (sum of

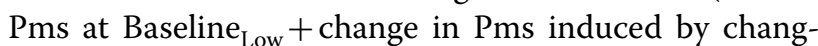
ing the dose of NE + change in Pms induced by PLR $\left._{\text {Low }}\right)$. If both values were significantly different, we considered that our hypothesis was valid.

In order to test the same hypothesis, we also compared in each patient the relative changes in Pms induced by PLR ( $\Delta \mathrm{Pms})$ at the high $\left(\Delta \mathrm{Pms}_{\mathrm{High}}\right)$ and the low dose $\left(\Delta \mathrm{Pms}_{\text {Low }}\right)$ of NE. If $\Delta \mathrm{Pms}_{\text {Low }}$ was lower than $\Delta \mathrm{Pms}_{\mathrm{High}}$, 
we considered that decreasing NE reduced the efficacy of a volume challenge on Pms.

The indexed arterial resistance was calculated as (mean arterial pressure - Pms)/CI and the indexed venous resistance as (Pms - CVP)/CI. Preload responsiveness at the highest and the lowest dose of NE was defined by an increase in $\mathrm{CI} \geq 10 \%$ during $\mathrm{PLR}_{\mathrm{High}}$ and $\mathrm{PLR}_{\mathrm{Low}}$, respectively [10].

\section{Statistical analysis}

Taking into account an $\alpha$ risk of $5 \%$ and a $\beta$ risk of $20 \%$, considering that the change in $\Delta \mathrm{Pms}$ induced by the modification in NE would be $8 \pm 15 \%[5,6]$, it was planned to include 30 patients. The normality of data distribution was assessed visually.

Data are expressed as median [interquartile range], mean [standard deviation] or frequency (n, \%), as appropriate. $\Delta \mathrm{Pms}_{\mathrm{High}}$ and $\Delta \mathrm{Pms}_{\text {Low }}$ were compared using a Wilcoxon test. For the other variables, the comparisons between the different times of the study were performed using a Friedman test or ANOVA for repeated measurements, followed by a pairwise comparison of variables according to Conover [18] as appropriate. Comparisons between subgroups were performed using a MannWhitney $U$ test. The relationship between variables was tested using the Spearman correlation. There were no missing data. The statistical analysis was performed using MedCalc 11.0.0 software (MedCalc, Mariakerke, Belgium) and reviewed by statisticians of our institution.

\section{Results}

\section{Patient characteristics}

Thirty patients were included 6.0 [4.4] days after the onset of septic shock. No patient met the exclusion criteria. No patients received a catecholamine other than NE (Table 1). Twelve (40\%) patients were known to have hypertension. All patients received sedation, and 23 (77\%) received neuromuscular blocking agents. For five (17\%) patients, continuous veno-venous haemofiltration was in progress during the measurements, without fluid removal. Seven (23\%) patients were in atrial fibrillation. Fifteen (50\%) patients received corticosteroids (hydrocortisone $200 \mathrm{mg} /$ day) (Table 1). Considering all timepoints in the study, the coefficient of determination of regression lines built for estimating Pms was $r^{2}=0.91$ [0.83-0.98].

\section{Effects of PLR}

The first PLR, performed at the highest dose of NE, significantly increased Pms by 13 [9-19]\% compared to Baseline $_{\text {High }}$ (Table 2, Fig. 2). The resistance to venous return did not significantly change. During $\mathrm{PLR}_{\mathrm{High}}, \mathrm{CI}$
Table 1 Patient characteristics at baseline

\begin{tabular}{|c|c|}
\hline Age (years) & $70[12]$ \\
\hline $\mathrm{M} / \mathrm{F}$ ratio & $25 / 5$ \\
\hline SAPS ॥ & $55[14]$ \\
\hline \multicolumn{2}{|l|}{ Source of sepsis } \\
\hline Lung $(n(\%))$ & $22(73 \%)$ \\
\hline Abdomen $(n(\%))$ & $6(20 \%)$ \\
\hline Catheter (n (\%)) & $2(7 \%)$ \\
\hline Lactate (mmol/L) & $2.6[3.8]$ \\
\hline $\mathrm{PaO}_{2} / \mathrm{FiO}_{2}(\mathrm{mmHg})$ & 142 [132-198] \\
\hline Tidal volume (mL/kg predicted body weight) & $4.8[0.9]$ \\
\hline Respiratory rate (breaths/min) & $30[16]$ \\
\hline $\operatorname{PEEP}\left(\mathrm{cmH}_{2} \mathrm{O}\right)$ & $11[4]$ \\
\hline Plateau pressure $\left(\mathrm{cmH}_{2} \mathrm{O}\right)$ & $26[4]$ \\
\hline Compliance of the respiratory system $\left(\mathrm{mL} / \mathrm{cmH}_{2} \mathrm{O}\right)$ & $36[10]$ \\
\hline
\end{tabular}

$N=30$. Data are expressed as numbers (\%) or mean [standard deviation] or median [interquartile range]

$\mathrm{F}_{\mathrm{i}} \mathrm{O}_{2}$, inspired fraction of oxygen; $\mathrm{M} / \mathrm{F}$, males/females; $\mathrm{P}_{\mathrm{a}} \mathrm{O}_{2}$, arterial oxygen partial pressure; PEEP, positive end-expiratory pressure; SAPS: Simplified Acute Physiologic Score

significantly increased by $6[2-10] \%$ and it increased by $\geq 10 \%$ in $8(27 \%)$ patients, indicating preload responsiveness (Table 2).

\section{Effects of decreasing NE}

The dose of NE decreased from 0.32 [0.18-0.62] to 0.26 $[0.13-0.50] \mu \mathrm{g} / \mathrm{kg} / \mathrm{min}(p<0.001)$ (Table 2). Additional file 1: table S1 describes the NE change per patient during the study. The time between the decrease in NE and Baseline $_{\text {Low }}$ was 38 [32-48] min. During this time, the fluid balance was -1 [ -18 to 22$] \mathrm{mL}$.

With this modification of NE, the mean arterial pressure decreased by $10[7-20] \% \quad(p<0.001)$. Pms decreased by $9[4-19] \%(p<0.001)$ (Table 2$)$. CI decreased by $11[3-16] \%(p<0.001)$.

The NE-induced change in Pms (expressed either in absolute value or percentage) was significantly correlated with the amplitude of the change in NE dose $(r=0.66, p<0.01)$. It was correlated with the diastolic arterial pressure at Baseline $\mathrm{High}(r=0.62, p=0.0003)$ and with the Pms at Baseline $\mathrm{High}_{\mathrm{g}}(r=0.48, p<0.01)$.

\section{Effects of PLR}

PLR $_{\text {Low }}$ significantly increased Pms by $11[6-16] \%$ com-

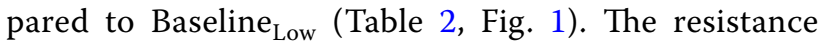
to venous return did not change significantly. During $\mathrm{PLR}_{\text {Low }}$, CI significantly increased by 10 [7-15]\% on average and it increased by $\geq 10 \%$ in $15(50 \%)$ patients (Table 2). 
Table 2 Haemodynamic variables during the study protocol

\begin{tabular}{|c|c|c|c|c|}
\hline & \multicolumn{2}{|c|}{ High dose of NE } & \multicolumn{2}{|c|}{ Low dose of NE } \\
\hline & Baseline & PLR & Baseline & PLR \\
\hline SAP $(\mathrm{mmHg})$ & 141 [25] & $146[25]$ & $120[17]^{b}$ & $127[23]^{c}$ \\
\hline $\mathrm{DAP}(\mathrm{mmHg})$ & $60[9]$ & $63[11]^{a}$ & $54[7]^{\mathrm{b}}$ & $58[8]^{c}$ \\
\hline MAP $(m m H g)$ & 88 [12] & $94[13]$ & $76[8]^{b}$ & $80[10]^{c}$ \\
\hline Heart rate (beats/min) & $93[16]$ & $96[15]$ & $92[14]$ & $96[14]$ \\
\hline $\mathrm{CVP}(\mathrm{mmHg})$ & $13.0[5.0]$ & $15.8[5.8]^{\mathrm{a}}$ & $12.4[5.2]$ & $14.3[5.9]^{c}$ \\
\hline Pms (mmHg) & $30.7[10.3]$ & $35.6[11.2]^{\mathrm{a}}$ & $27.7[9.7]^{b}$ & $30.5[10.4]^{c}$ \\
\hline Pms-PVC (mmHg) & $17.6[9.8]$ & $19.7[11.2]$ & $15.3[9.7]^{\mathrm{b}}$ & $16.2[9.8]$ \\
\hline Indexed venous resistance $\left(\mathrm{mmHg} \cdot \mathrm{min} \cdot \mathrm{m}^{2} / \mathrm{L}\right)$ & $5.4[2.7]$ & $5.5[2.9]$ & $4.9[2.7]$ & $4.7[2.3]$ \\
\hline Indexed arterial resistance (mmHg.min. $\left.\mathrm{m}^{2} / \mathrm{L}\right)$ & $17.7[8.3]$ & $16.4[10.0]^{a}$ & $15.6[6.1]^{b}$ & $14.4[6.1]$ \\
\hline Cardiac index $\left(\mathrm{L} / \mathrm{min} / \mathrm{m}^{2}\right)$ & $3.24[0.9]$ & $3.57[0.9]^{\mathrm{a}}$ & $3.08[0.7]^{b}$ & $3.43[0.8]^{c}$ \\
\hline Dose of $N E(\mu \mathrm{g} / \mathrm{kg} / \mathrm{min})$ & $0.32[0.2-0.6]$ & $0.32[0.2-0.6]$ & $0.26[0.1-0.5]^{b}$ & $0.26[0.1-0.5]$ \\
\hline Cardiac function index (/min) & $4.8[1.3]$ & & $4.9[1.5]$ & \\
\hline
\end{tabular}

$N=30$. Data are expressed as mean [standard deviation]

CVP, central venous pressure; DAP, diastolic arterial pressure; MAP, mean arterial pressure; NE, norepinephrine, Pms, mean systemic pressure; SAP, systolic arterial pressure

${ }^{a} p<0.05$ PLR at high dose vs. baseline at high dose

${ }^{\mathrm{b}} p<0.05$ baseline at low dose vs. baseline at high dose

${ }^{c} p<0.05$ baseline at low dose vs. PLR at low dose

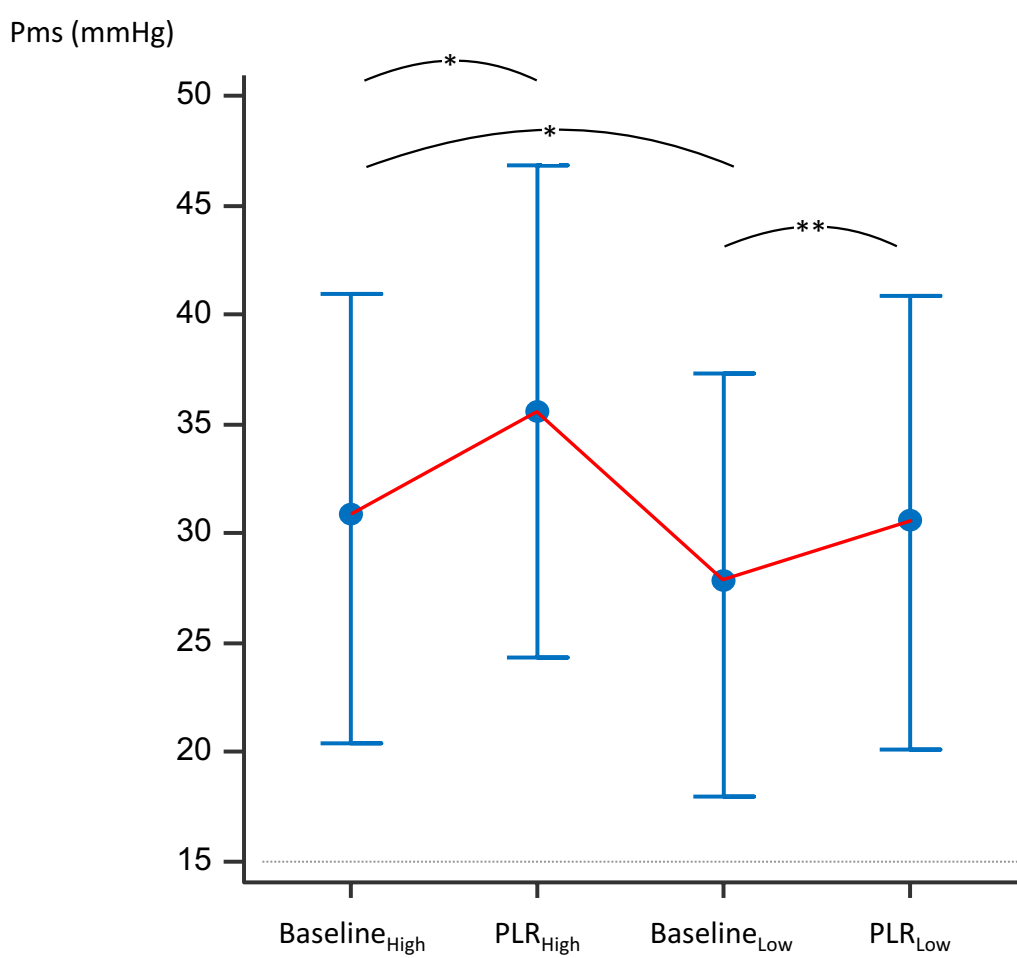

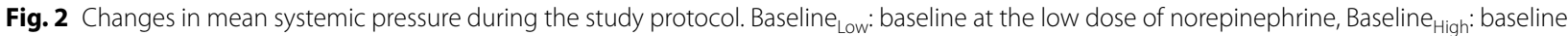
at the high dose of norepinephrine, $P L R_{\text {Low }}$ : passive leg raising at the low dose of norepinephrine; $P L R_{\text {High: }}$ passive leg raising at the high dose of norepinephrine, Pms: mean systemic pressure. ${ }^{*} p<0.05$ vs. Baseline High ${ }^{* *} p<0.05$ vs. Baseline Low. $N=30$, mean [standard deviation] 
Comparison between $\triangle \mathrm{Pms}$ induced by $\mathrm{PLR}_{\text {Low }}$ and $\mathrm{PLR}_{\text {High }}$ Pms at $P_{L R}$ High was significantly higher than the sum: Pms at Baseline $_{\text {Low }}+\left(\right.$ Pms at Baseline High $_{-}-$Pms at Baseline $\left._{\text {Low }}\right)+\left(\right.$ Pms at PLR $_{\text {Low }}$ - Pms at Baseline Low $)$ (35.6 [11.2] $\mathrm{mmHg}$ vs. 33.6 [10.9] $\mathrm{mmHg}$, respectively, $p<0.01)$. The $\Delta \mathrm{Pms}$ induced by $\mathrm{PLR}_{\mathrm{High}}$ was significantly larger than the $\Delta \mathrm{Pms}$ induced by $\mathrm{PLR}_{\mathrm{Low}}(13$ [9-18] \% vs. $11[6-15] \%, p<0.001$ ) (Fig. 3). The increase in CI induced by PLR $_{\text {Low }}$ was significantly larger than the increase in CI induced by $\operatorname{PLR}_{\text {High }}(p<0.01)$ (Table 2 ).

$\Delta \mathrm{Pms}_{\text {High }}-\Delta \mathrm{Pms}_{\text {Low }}$ was not significantly correlated with the NE-induced $\Delta \mathrm{Pms}(p=0.30)$, with the change of the NE dose from Baseline High $_{\text {to }}$ Baseline Low $(p=0.23)$, with the diastolic arterial pressure at Baseline ${ }_{\mathrm{High}}$ $(p=0.88)$, with the NE-induced change in mean arterial pressure $(p=0.56)$, with the PEEP level at baseline $(p=0.68)$, and with the airway driving pressure $(p=0.39)$. It was correlated with the airway plateau pressure at baseline $(r=0.45, p=0.02) . \Delta \mathrm{Pms}_{\text {High }}-\Delta \mathrm{Pms}_{\text {Low }}$ was not different between the half of the population with the smallest drop in norepinephrine and the half with the greatest drop $(1.15[0.52-1.51] \mathrm{mmHg}$ and 2.07 [1.162.41] $\mathrm{mmHg}$, respectively, $p=0.06$ ).

The change of Pms from Baseline $\mathrm{High}_{\text {to Baseline }}$ Low significantly correlated with the simultaneous change in the NE dose $\left(r^{2}=0.34, p<0.01\right)$ (Additional file 1: figure S2).

\section{Discussion}

This study suggests that the PLR-induced increase in Pms $(\triangle \mathrm{Pms})$ is larger at a higher dose of NE compared to a lower dose. The $\Delta$ Pms induced by PLR at a higher dose of NE was larger than the addition of the effects on Pms of changing the dose of NE and performing a PLR at a lower NE dose. It also confirms that decreasing the dose of NE significantly decreases Pms ("fluid-like" effect of $\mathrm{NE}$ ). These results suggest that NE improves the haemodynamic efficacy of fluid administration.

$\mathrm{NE}$ is the first-line vasopressor in septic shock [19]. While NE is mainly used for restoring arterial pressure through arterial vasoconstriction, its effects on the venous circulation are likely important. The stimulation

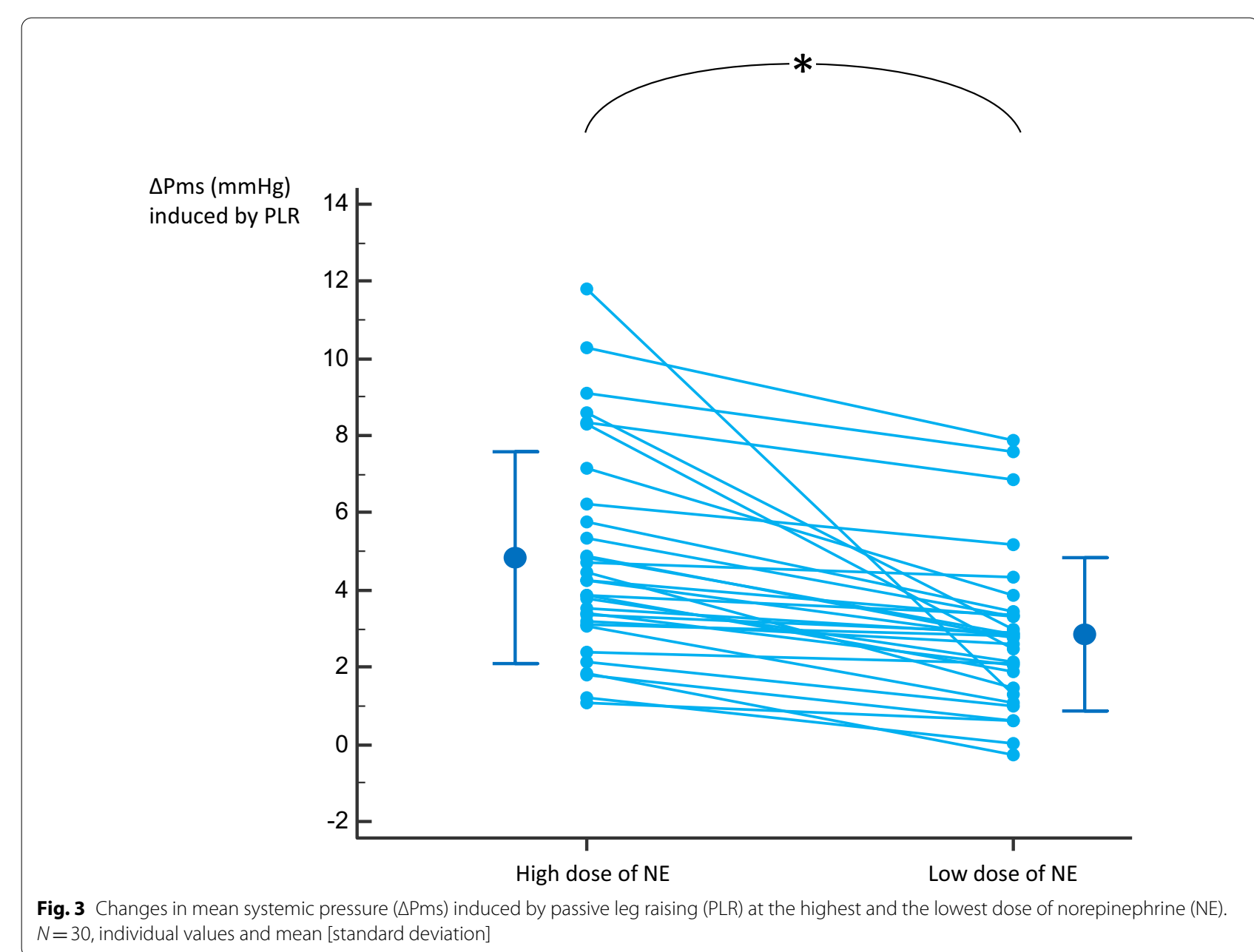


of the venous $\alpha$-receptors induces venoconstriction, which increases the stressed blood volume and reduces the unstressed blood volume. Datta and Magder have evidenced this for the first time in animals [3]. More recently, some methods were developed for investigating the determinants of venous return in critically ill patients. In particular, Maas and co-workers elegantly described the heart-lung interactions method that we used in the present study $[1,20]$. These studies conducted in septic shock patients confirmed that NE increases Pms $[1,2]$. It also increases the resistance to venous return but to a smaller extent. As a result, NE increases the venous return and cardiac output in preload-dependent patients $[2,5]$. Our study confirms these previous findings; Pms was significantly higher at the highest dose of NE. At this dose, the proportion of preload responsive cases was lower, and the PLR-induced increase in CI was also smaller. In this regard, the effects of NE on venous return mimic those of fluid administration.

The present study extends these findings. In septic shock patients, the increase in Pms induced by PLR, which mimics fluid administration, was significantly larger at the highest dose of NE than at the lowest. This suggests that at the highest dose of NE, the PLR increased the proportion of stressed blood volume to a larger extent than at the lowest dose. PLR (or fluid administration) at the lowest degree of vein constriction still increases the proportion of stressed blood volume, but to a lower extent than the same volume at high dose. In other words, the blood transfer of PLR might occur on a constricted venous network, which enhanced its haemodynamic efficacy. This corroborates the observation made by Harrois et al. that NE decreases fluid requirements during fluid resuscitation of uncontrolled haemorrhagic shock in mice [21]. The present study reports such an effect for the first time in septic shock patients despite the decrease in the dose of NE was small. Of note, the PLR-induced change in Pms was not correlated with the amplitude of the dose decrease in NE. This reflects the fact that the vascular reactivity is very variable from one patient to another, even at this post-acute phase of septic shock.

The PLR was used in order to reproduce the haemodynamic effects of fluid administration but in a reversible way. Otherwise, the comparison of the haemodynamic condition at the two NE doses would not have been possible. In fact, the volume of venous blood transferred towards the heart chambers during PLR might have been different under the two doses of NE. Indeed, at the highest dose, the volume of the constricted splanchnic and inferior limbs venous compartment was less, such that less blood volume might have been mobilised during PLR than at the lowest dose. Nevertheless, if it was the case, this would tend to reduce (not increase) the PLR-induced increase in Pms, which even reinforces the conclusions of the study.

In the intensive care unit, a positive fluid balance is deleterious and increases mortality [22-24]. The present results suggest that a possible interest of NE would be to limit the volume of fluid administered [21]. Together with the fact that it can restore arterial pressure rapidly in case of life-threatening hypotension, this may support the strategy to infuse NE early in the course of septic shock [25]. Septic shock resuscitation in the first hours requires fluid administration in order to correct hypoperfusion. Co-administration of fluid and NE by the effect described in our study, might increase the fluid efficacy on venous return and correct hypoperfusion faster in septic shock patients. This is in concordance with the observation that an early administration of NE reduced the total cumulative fluid balance and was associated with a reduction of mortality $[24,26]$.

Besides the methodological bias discussed above, our study has limitations. First, we investigated decreases rather than increases of NE in patients that had been already resuscitated. This was justified by the need of performing measurements during haemodynamic stability, which would have been impossible to observe in hypotensive patients at the initial phase of septic shock. Even though there is no pharmacological reason why the venous effects of NE should differ in direction when its dose is increased rather than decreased, performing our study in patients who would need an increase in the dose of NE, i.e. hypotensive patients, may have led to larger dose changes. Second, the change in NE dose was decided by the attending physicians in order to target their predefined goal of a mean arterial pressure. The dose decrease was not standardised, as it would have been possible in animal studies. Third, NE might exert a slight inotropic effect [4], which would reduce Pms and counterbalance the increase in Pms at the highest NE dose. The lack of change in the cardiac function index belies this assumption. However, it cannot be ruled out that left ventricular contractility may have increased anyway, because the cardiac function index, like the left ventricular ejection fraction [27], tends to decrease as ventricular afterload increases.

\section{Conclusions}

This study showed that NE enhances the increase in Pms induced by a PLR manoeuvre. These results suggest that a bolus of fluid of the same volume has a greater haemodynamic effect at a high dose than at a low dose of norepinephrine during septic shock. 


\section{Abbreviations}

Cl: Cardiac index; CVP: Central venous pressure; $\triangle \mathrm{Pms}_{\text {High }}$ : PLR-induced increase in Pms at the highest dose of $\mathrm{NE} ; \triangle \mathrm{Pms}_{\text {Low }}$ : PLR-induced increase in Pms at the lowest dose of NE; NE: Norepinephrine; PEEP: Positive end-expiratory pressure; PLR: Passive leg raising; Pms: Mean systemic pressure.

\section{Supplementary Information}

The online version contains supplementary material available at https://doi. org/10.1186/s13054-021-03711-5.

Additional file 1: figure S1: Heart-lung interactions method for estimating the determinants of venous return. Example of the estimation of the venous return curve and its determinants with the heart-lung interactions method in a typical patient. figure $\mathbf{S 2}$ : Correlation between the changes in mean systemic pressure induced by decreasing the dose of norepinephrine and the amplitude of the dose decrease. The change in the mean systemic pressure is on the $y$ axis and the amplitude of the dose decrease on the $x$ axis. table S1: Norepinephrine change per patient. This table describes the dose of NE before and after its decrease.

\section{Acknowledgements}

We are thankful to Drs. Alexandra ROUQUETTE and Hélène AGOSTINI and to Prof. Laurence MEYER from the Clinical Research Unit of the Bicêtre Hospital, for their help in statistical analyses.

\section{Authors' contributions}

IA performed the acquisition, analysis, and interpretation of data and drafted the manuscript. CL contributed to the acquisition, analysis and interpretation of data and to drafting the manuscript. J-LT conceived and designed the study, contributed to the acquisition, analysis and interpretation of data and to drafting the manuscript. LG contributed to the acquisition of data and drafting the manuscript. FG contributed to the acquisition of data and drafting the manuscript. XM conceived and designed the study, analysed and interpreted data and drafted the manuscript. They all agree to be accountable for all aspects of the work in ensuring that questions related to the accuracy or integrity of any part of the work are appropriately investigated and resolved. All authors read and approved the final manuscript.

\section{Funding}

This study received institutional funding from the Assistance publique-Hôpitaux de Paris. Dr. Imane ADDA was granted by the French ministry of health ("Année recherche").

\section{Availability of data and materials}

The datasets used during the current study are available from the corresponding author on reasonable request.

\section{Declarations}

\section{Ethics approval and consent to participate}

This study was approved by the institutional review board of our institution (Comité pour la protection des personnes Ile-de-France VII). Patients or their next of kin were informed about the study and accepted to participate.

\section{Consent for publication}

All authors consented for publication of the study.

\section{Competing interests}

J-LT and XM are members of the medical advisory board of Pulsion Medical Systems, Getinge. The other authors have no conflict of interest to declare.

Received: 26 April 2021 Accepted: 28 July 2021

Published online: 21 August 2021

\section{References}

1. Maas JJ, Pinsky MR, de Wilde RB, de Jonge E, Jansen JR. Cardiac output response to norepinephrine in postoperative cardiac surgery patients: interpretation with venous return and cardiac function curves. Crit Care Med. 2013:41(1):143-50.

2. Persichini R, Silva S, Teboul J-L, Jozwiak M, Chemla D, Richard C, et al. Effects of norepinephrine on mean systemic pressure and venous return in human septic shock. Crit Care Med. 2012;40(12):3146-53.

3. Datta P, Magder S. Hemodynamic response to norepinephrine with and without inhibition of nitric oxide synthase in porcine endotoxemia. Am J Respir Crit Care Med. 1999;160(6):1987-93.

4. Hamzaoui O, Jozwiak M, Geffriaud T, Sztrymf B, Prat D, Jacobs F, et al. Norepinephrine exerts an inotropic effect during the early phase of human septic shock. Br J Anaesth. 2018;120(3):517-24.

5. Monnet X, Jabot J, Maizel J, Richard C, Teboul J-L. Norepinephrine increases cardiac preload and reduces preload dependency assessed by passive leg raising in septic shock patients. Crit Care Med. 2011;39(4):689-94.

6. Guérin L, Teboul J-L, Persichini R, Dres M, Richard C, Monnet X. Effects of passive leg raising and volume expansion on mean systemic pressure and venous return in shock in humans. Crit Care. 2015;19:411.

7. Shankar-Hari M, Phillips GS, Levy ML, Seymour CW, Liu VX, Deutschman CS, et al. Developing a new definition and assessing new clinical criteria for septic shock: for the third international consensus definitions for sepsis and septic shock (Sepsis-3). JAMA. 2016;315(8):775-87.

8. Asfar P, Meziani F, Hamel J-F, Grelon F, Megarbane B, Anguel N, et al. High versus low blood-pressure target in patients with septic shock. N Engl J Med. 2014;370(17):1583-93.

9. Cooke K, Sharvill R, Sondergaard S, Aneman A. Volume responsiveness assessed by passive leg raising and a fluid challenge: a critical review focused on mean systemic filling pressure. Anaesthesia. 2018;73(3):313-22.

10. Monnet $X$, Teboul J-L. Passive leg raising: five rules, not a drop of fluid! Crit Care. 2015;19:18.

11. Annane D, Ouanes-Besbes L, de Backer D, Du B, Gordon AC, Hernández G, et al. A global perspective on vasoactive agents in shock. Intensive Care Med. 2018;44(6):833-46

12. Wijnberge $M$, Sindhunata DP, Pinsky MR, Vlaar AP, Ouweneel $E$, Jansen $J R$, et al. Estimating mean circulatory filling pressure in clinical practice: a systematic review comparing three bedside methods in the critically ill. Ann Intensive Care. 2018;8(1):73.

13. Monnet $\mathrm{X}$, Teboul J-L. Transpulmonary thermodilution: advantages and limits. Crit Care. 2017;21(1):147.

14. Jozwiak M, Monnet $X$, Teboul J-L. Pressure waveform analysis. Anesth Analg. 2018;126(6):1930-3.

15. Monnet $X$, Persichini R, Ktari M, Jozwiak M, Richard C, Teboul J-L. Precision of the transpulmonary thermodilution measurements. Crit Care. 2011;15(4):R204.

16. De Courson H, Ferrer L, Cane G, Verchère E, Sesay M, Nouette-Gaulain K, et al. Evaluation of least significant changes of pulse contour analysisderived parameters. Ann Intensive Care. 2019:9(1):116.

17. Monnet $X$, Teboul J-L. Assessment of fluid responsiveness: recent advances. Curr Opin Crit Care. 2018:24(3):190-5.

18. Conover WJ. Practical nonparametric statistics. 3rd ed. Hoboken: Wiley; 1999.

19. Scheeren TWL, Bakker J, De Backer D, Annane D, Asfar P, Boerma EC, et al. Current use of vasopressors in septic shock. Ann Intensive Care. 2019;9(1):20.

20. Maas JJ, Pinsky MR, Geerts BF, de Wilde RB, Jansen JR. Estimation of mean systemic filling pressure in postoperative cardiac surgery patients with three methods. Intensive Care Med. 2012;38(9):1452-60.

21. Harrois A, Baudry N, Huet O, Kato H, Dupic L, Lohez M, et al. Norepinephrine decreases fluid requirements and blood loss while preserving intestinal villi microcirculation during fluid resuscitation of uncontrolled hemorrhagic shock in mice. Anesthesiology. 2015;122(5):1093-102.

22. Haas LEM, Karakus A, Fijen JW, de Lange DW, Vincent J-L, Sakr Y, et al. True changes in patient characteristics and outcomes or partially a reflection of different study populations?: discussion on «Comparison of European ICU patients in 2012 (ICON) versus 2002 (SOAP)». Intensive Care Med. 2018;44(7):1195-6. 
23. Malbrain MLNG, Van Regenmortel N, Saugel B, De Tavernier B, Van Gaal P-J, Joannes-Boyau O, et al. Principles of fluid management and stewardship in septic shock: it is time to consider the four D's and the four phases of fluid therapy. Ann Intensive Care. 2018;8(1):66.

24. Marik PE, Linde-Zwirble WT, Bittner EA, Sahatjian J, Hansell D. Fluid administration in severe sepsis and septic shock, patterns and outcomes: an analysis of a large national database. Intensive Care Med. 2017:43(5):625-32.

25. Hylands M, Toma A, Beaudoin N, Frenette AJ, D'Aragon F, Belley-Côté É, et al. Early vasopressor use following traumatic injury: a systematic review. BMJ Open. 2017;7(11):e017559.
26. Bai X, Yu W, Ji W, Lin Z, Tan S, Duan K, et al. Early versus delayed administration of norepinephrine in patients with septic shock. Crit Care. 2014;18(5):532.

27. Robotham JL, Takata M, Berman M, Harasawa Y. Ejection fraction revisited. Anesthesiology. 1991;74(1):172-83.

\section{Publisher's Note}

Springer Nature remains neutral with regard to jurisdictional claims in published maps and institutional affiliations.
Ready to submit your research? Choose BMC and benefit from:

- fast, convenient online submission

- thorough peer review by experienced researchers in your field

- rapid publication on acceptance

- support for research data, including large and complex data types

- gold Open Access which fosters wider collaboration and increased citations

- maximum visibility for your research: over $100 \mathrm{M}$ website views per year

At BMC, research is always in progress.

Learn more biomedcentral.com/submissions 